\title{
UNA "HEREDERA INFIEL" EN LOS INICIOS DE LA SOCIEDAD DE MASAS, VICTORIA OCAMPO, ARGENTINA, AÑOS VEINTE
}

Uma "herdeira infiel" no início da sociedade de massa, Victoria Ocampo, Argentina, 1920

An "unfaithful heiress" in the origins of mass society, Victoria Ocampo, Argentina, 1920s

\author{
MARÍA SOLEDAD GONZÁLEZ ${ }^{I^{*}}$
}

DOI: http://dx.doi.org/10.1590/S2178-14942020000200009

Instituto de Geografía, Historia y Ciencias Sociales, Consejo Nacional de Investigaciones Científicas y Técnicas, Universidad Nacional del Centro de la Provincia de Buenos Aires (UNCPBA), Argentina.

*msgonzalez@live.com.ar

(D) https://orcid.org/0000-0003-1460-1176

Artículo recibido en el 31 de Diciembre de 2019 e aprobado para publicación en el 20 de Marzo de 2020. 


\title{
RESUMEN
}

En el presente artículo nos proponemos analizar a Victoria Ocampo (1890-1979) como gestora artística y cultural en la Argentina de los años veinte. Recurrimos para esto a las categorías en torno al género y la clase y la noción de "heredera infiel". Realizamos este abordaje a partir de "Viraje", cuarto volumen de su Autobiografía y algunas revistas de actualidades de la época. Sostenemos como hipótesis que Ocampo comienza a posicionarse mediante la articulación de lo público y lo privado sobre las áreas de vacancia del Estado, deseadas por la clase dirigente en los comienzos de una sociedad de masas.

PALABRAS CLAVE: Victoria Ocampo; Género; Clase; Estado; Herencia; Sociedad de masas.

\begin{abstract}
In this article we propose to analyze Victoria Ocampo (1890-1979) as an artistic and cultural manager in Argentina in the 1920s. For this, we resort to the categories around gender and class and the notion of "unfaithful heiress". We carry out this approach from the fourth volume of Viraje's Autobiography and some current news magazines of the time. We hypothesize that Ocampo originally positions herself through the articulation of the public and the private vacancy areas of the State, desired by the ruling class at the beginning of a mass society.
\end{abstract}

KEYWORDS: Victoria Ocampo; Gender; Class; State; Heritage; Mass society.

\section{Resumo}

Neste artigo, propomos analisar Victoria Ocampo (1890-1979) como gerente artística e cultural na Argentina da década de 1920. Para isso, recorremos às categorias de gênero e classe e à noção de "herdeira infiel". Realizamos essa abordagem com base em "Viraje", quarto volume de sua autobiografia e em algumas revistas atuais da época. Nossa hipótese é que Ocampo comece a se posicionar através da articulação do público e do privado sobre as áreas vagas do Estado, desejadas pela classe dominante no início de uma sociedade de massa.

PALAVRAS-CHAVE: Victoria Ocampo; Gênero; Classe; Estado; Herança; Sociedade de massa. 


\section{INTRODUCCIÓN}

$\mathrm{E}$ presente artículo se propone analizar el agenciamiento de Victoria Ocampo durante los años veinte del siglo pasado, momento en que la misma comenzó a asomar en la escena pública. Busca descentrar el análisis de Ocampo reproblematizando algunas cuestiones abordadas en González (2018) a partir del aporte de María Celia Vázquez (2019) que remite a que la misma intenta agenciarse un lugar en el espacio público a través de una voz propia que articula lo privado y lo público. A partir del diálogo interdisciplinario, leeremos a Ocampo como escritora y "gestora artística y cultural" 1 . De allí que sostenemos la hipótesis de que es a partir de los años veinte del siglo pasado que Ocampo comienza a posicionarse como escritora y gestora ocupando los lugares dejados vacantes por el Estado, espacios deseados en el contexto de los inicios de una sociedad de masas. Por esto, proponemos interpretarla a partir de la noción de "heredera infiel" (Derrida; Roudinesco, 2009) entendiéndola como quien toma el legado de su familia en tanto parte de la clase dirigente y lo transforma en un agenciamiento multiple ${ }^{2}$, literario, artístico, social y cultural. Por tanto consideramos que Ocampo responde a una doble exigencia y una tarea contradictoria, por un lado saber reafirmar lo que está antes (ya que no está en condiciones de elegir) y asimismo decidir en tanto sujeto libre. Ocampo reactiva y mantiene con vida su herencia, esta la elige, pero Victoria la mantiene con vida aunque por momentos esto signifique destruirla ${ }^{3}$.

Optamos por una periodización en los años veinte ya que nos permite pensar a Ocampo antes de Sur, cuestión que si ha sido extensamente abordada (Gramuglio, 1983; 1986; King, 1989; Pasternac, 2002; Sitman, 2003). Asimismo, dentro de ese marco, podemos empezar a abordar los inicios de su agenciamiento articulador de lo público y privado. Recurrimos para esto a su Autobiografía, en concreto a "Viraje", cuarto volumen que se publicó luego de su muerte, donde aborda el periodo que ella misma periodiza entre 1924 y 1929 y añadiremos a este, el análisis de la recepción que Ocampo tuvo durante los veinte a partir de la recepción que realizaron algunas revistas de actualidades de la época. Nos valdremos para ello de las herramientas que nos propician los estudios de género (Barrancos, 2008; Scott, 2008; Femenías, 2019) y el cruce con la clase (Jelin, 2014).

\section{GÉNERO E HISTORIA}

L a recuperación de las mujeres como sujetos históricos ha sido un arduo trabajo de la historiografía desde las últimas décadas del siglo XX. Claro está que no han sido los únicos sujetos abordados en este proceso de renovación disciplinar, también lo fueron los trabajadores, los niños y los pobres, entre otros. En ese marco la historia de las mujeres asomaría 
lentamente. Visibilizarlas fue el primer paso de una historia con mujeres para luego incorporar categorías que tensionaran con preguntas nuevas las investigaciones, teniendo en cuenta no solo a las mujeres sino también a los varones. La categoría de género ha sido central, el aporte de Scott (2008) permitió entender a esta como conocimiento de la diferencia sexual y a esa diferencia sexual como social y cultural y no natural. Por esto la autora señalaría al respecto que: "la forma en que esta nueva historia debería incluir y dar cuenta de la experiencia de las mujeres depende de la amplitud con que pudiera desarrollarse el género como categoría de análisis" (Scott, 2008: 3). Por tanto, romper con los esencialismos es también advertir que cuando se analiza a las mujeres como sujetos históricos desde la perspectiva de género no se deja de lado la visión de los varones (Valobra y Nállim, 2016). La obra de Joan Scott es relevante también con relación a la noción de "experiencia" que realiza nutrida de los estudios feministas y los estudios culturales (Garazi, 2016). Otra renovación en las humanidades y ciencias sociales que han producido los estudios de género se refiere a reproblematizar la división público-privado y "la 'interioridad femenina' como algo dado" (Arfuch, 2016: 250). Al revisarse la categoría de esfera pública y público/privado, los nuevos aportes criticaron las divisiones tajantes y pensaron en términos de porosidad e interrelación ${ }^{4}$. Entonces, las experiencias personales y subjetivas como asimismo las actividades públicas y políticas fueron materia de análisis. Con relación a Victoria Ocampo algunos trabajos como los de Sarlo (1988; 2007) desde la historia cultural de las mujeres y Queirolo (2009) en clave del entrecruzamiento entre género, clase e intelectuales permitieron sin dudas comenzar a abordarla intensamente. Sin embargo, aunque Sarlo desde la crítica literaria recuperó a Ocampo, no lo hizo desde la perspectiva de género y por tanto no se detuvo en el análisis de las tensiones que esta categoría si permite abordar. Por su parte, el análisis de Queirolo (2009) que sí contiene un interesante enfoque de género, profundizó sobre las preguntas por la emancipación y por los feminismos en Ocampo. Sin desconocer la importancia de estos trabajos, los retomaremos a la luz del entrecruzamiento entre género y clase presente en González (2018), profundizando en algunas cuestiones ligadas a los comienzos de la agencia de Ocampo en los veinte solo tratadas allí preliminarmente. Recurriremos asimismo al trabajo de Vázquez (2019) para analizar la articulación público-privado.

Con relación a la autobiografía y sus problemas, ya se ha advertido que el estudio crítico de la misma puede constituirse como tal potenciando sus contradicciones (Topuzian, 2003: 273-274). Esta se convierte, en una suerte de autopreservación y de coartada (Kadir, 1995: 15), donde Victoria deja en claro desde que tradición pretende ser leída. En suma, profundizando sobre el abordaje de Ocampo y su escritura podemos afirmar que su trabajo como gestora no es un adicional a su escritura o una mera sumatoria sino que se convierte en una 
de las maneras por las cuales Ocampo construye la tradición desde la que pretende ser leída. Como expresó Podlubne (2016: 86): "Fiel a la creencia de los autobiógrafos tradicionales, confiaba en las posibilidades retóricas y gráficas de conjurar sus efectos, dejando establecido cómo se la debería recordar en adelante".

Por esto, atender a su trayectoria individual relacionándola con la organización social, y las interrelaciones entre género y clase (Jelin, 2014) se convierte en una herramienta heurística y conceptual de importancia. Asimismo, el análisis del discurso de Ocampo junto con el tratamiento de algunas de sus intervenciones a partir del abordaje de las revistas de actualidades de la época, permiten notar no solo la tracción de género sino también la flexión elitista de dicho agenciamiento que denotaba refinamiento y distinción de clase frente a los avances de una sociedad de masas.

En síntesis, el presente artículo se vale de la utilización de las herramientas que propician el abordaje de las interseccionalidades entre género y clase y asimismo del aporte de Derrida y Roudinesco (2009) que nos posibilitan descentrar a Ocampo y leerla a partir de la noción de "heredera infiel". El enfoque semiótico-discursivo de lo cultural y social nos permite realizar un análisis de la identidad, la alteridad y la diferencia. (Richard, 2018: 30). La narrativa ha adquirido en los últimos tiempos gran importancia para la historia, la teoría literaria y las Ciencias Sociales. Es por tanto pertinente atender al discurso y su temporalidad, bucear sobre las representaciones y narrativas presentes en la escritura de Ocampo y ver de qué manera se interrelacionan en una conjunción de espacio y tiempo mediada por el afecto, en términos de Bajtin un "cronotopos" (Arfuch, 2016). De allí un espacio de indagación ineludible que remite al análisis de la subjetividad y las estrategias narrativas en la escritura de Ocampo. En suma, repensar a Ocampo y releerla en los veinte a partir de los estudios de género, como escritora y gestora desde un abordaje interdisciplinario que permita una lectura histórica, política, social y cultural.

\section{UNA “HEREDERA INFIEL"}

$\mathrm{E}$ n 1972, al momento de insertar su nombre en el Diccionario Biográfico de Mujeres Argentinas, Lily Sosa de Newton (1972: 252) definió a Victoria como "escritora". Nacida a fines del siglo XIX en el seno de una de las familias más importantes de la alta sociedad porteña, fue la hija mayor del matrimonio entre Manuel Ocampo y Ramona Aguirre, unión de la cual nacerían cinco mujeres más: Angélica, Pancha, Rosa, Clara y Silvina. Ya desde su temprana adolescencia Victoria comenzaría a interesarse por las letras, tarea que desarrollaría no sin resistencias familiares y sociales. Antes había mostrado también una clara inclinación 
hacia el teatro, deseo frustrado por mandato familiar. Al respecto señala Vázquez (2019: 12): "a propósito de su carrera literaria y, en referencia a la vocación fallida de actriz, Victoria Ocampo se declara periodista por no decirse escritora" ${ }^{5}$. Aunque la obra de Victoria es por lo general reconocida por la revista Sur que fundó y dirigió desde 1931 y la editorial del mismo nombre creada en 1933, su irrupción en la esfera pública comienza antes, en los años veinte y es a partir de su rol como escritora, lugar no reconocido abiertamente por ella misma y por lo general descuidado por la crítica, salvo la excepción de la "cronista outsider" recuperada recientemente por Vázquez (2019). En este trabajo sostendremos como hipótesis que de manera conjunta a esa profunda labor como escritora Ocampo desarrolló una intensa tarea como gestora artística y cultural. Y en ese sentido señalamos que ese agenciamiento, en la Argentina de los años veinte, puede entenderse en el marco de los lugares de vacancia que dejaba el Estado, que comenzaron a ser de interés en el marco de los inicios de una sociedad de masas. Es allí donde hace su irrupción Ocampo en la esfera pública para insertarse en lugares de vacancia codiciados por las elites corridas de sus lugares de poder, en el marco de las transformaciones sociales, políticas y culturales de la Argentina de los años veinte. Como señaló Cattaruza (2012), el mundo intelectual iba ganando autonomía a partir de criterios propios, uno de ellos el talento. Esa autonomía se vio favorecida por la aparición de revistas especializadas en literatura y cultura. Lo interesante en este proceso que analiza el autor es que:

Aunque era todavía un proceso acotado, se insinuaba la existencia de una relación más compleja y con más mediaciones entre la elite social y política y el mundo de la cultura. A comienzos de los años veinte era ya evidente que, junto al escritor ocasional, que era al mismo tiempo un personaje de la alta sociedad, se encontraban muchos otros que no exhibían ese origen social (Cattaruzza, 2012: 70).

Ese es pues el marco en que se inserta Victoria en la arena pública, su agencia puede entonces interpretarse a partir de los rompimientos de género: “En esa época, el mundo literario argentino estaba dominado por los hombres. Las mujeres escritoras eran una rareza y por lo general no se les permitía ser miembros de la 'sociedad' de autores profesionales serios" (Meyer, 1981: 85).

Publicar el ensayo Babel en La Nación en 1920, y el libro De Francesca a Beatrice en 1924, serían acciones considerables para una mujer de su clase. Si leemos la interesante crítica de Fray Mocho sobre la segunda edición de este libro, allí se apuntaba a destacar que: "Con este itinerario 'A través de la Divina Comedia' alcanza de golpe la señora Victoria Ocampo esa reputación intelectual que hoy disfruta" (PAPEL Y TINTA, 1929: 41). De ese año, 
nos referimos a 1929, también data su publicación "El infierno" en la revista Plus Ultra, de 10 de junio de 1929. Esas intervenciones de Victoria y las realizadas sobre su obra, coinciden precisamente con la fase en que ella misma cierra (y abre) la periodización del cuarto volumen de su Autobiografía "Viraje". Esto concuerda con el contexto en que comienza a hacerse un lugar destacado en lo público. Junto a esa profunda labor de escritora, Victoria comenzaría a posicionarse en la arena pública con mayor firmeza con relación a otra labor crucial la de "gestora artística y cultural". Sostenemos por tanto que Ocampo realiza una articulación entre lo público y lo privado como escritora y gestora artística y cultural y asimismo deja inscripta a partir de su escritura la tradición con que pretende ser leída.

Como otras mujeres de su época y de su clase, Victoria comenzó a asomar en la esfera pública a partir de la conquista de la escritura y su rol como gestora:

En la generación de Victoria, no por casualidad, aparecen varias mujeres de la buena sociedad porteña que encabezan organizaciones de estímulo cultural. Bebé Sansinena, las hermanas Del Carril, Adelia Acevedo, Tota Atucha, Magdalena Bengolea. Pagan a los maestros, dirigen el gusto, a veces lo tiranizan (Matamoro, 1986: 19).

En "Viraje" Victoria retrata su experiencia en los veinte, en una periodización que como ya señalamos, ella misma establece: "El año 1924 parece iniciar un nuevo ciclo que hará crisis hacia 1929" (Ocampo, 1982: 16).

El inicio de ese recorte en 1924 es ubicado por Victoria en el momento de irse a vivir sola y asimismo a partir de la presencia de dos figuras masculinas claves para ella con las que busca y consigue establecer contactos y así legitimarse en lo público: nos referimos a Tagore y Ansermet. Con la publicación de su libro De Francesca a Beatrice había conseguido codearse con Ortega y Gasset, figura de gran prestigio intelectual en nuestro país. A partir de aquí podemos notar como Victoria se mira y construye a partir de la mirada y legitimación masculina. Negocia con estos varones o estrecha vínculos de "amistad" porque es consciente de que debe hacerlo para agenciarse un lugar en lo público. De igual forma expresa que es su gran amor Julián Martínez, quien enuncia con su inicial J., quien la alienta a dedicarse a la escritura. Son por tanto los varones quienes habilitan a Ocampo en sus acciones. Tal es así que el cierre que elige Victoria se ubica en 1929 donde deja entrever la crisis final de su relación con J. y los comienzos del proyecto Sur, nombre sugerido por Ortega. En sus escritos también dirá que dicho proyecto lo llevaría a cabo por sugerencia masculina y allí desliza los nombres de Waldo Frank y Mallea, contacto con La Nación. En el marco de un mundo intelectual y cultural marcadamente androcéntrico, Ocampo establece estrategias interesantes de negociación a partir de su importante caudal económico, su posicionamiento social y sus 
recursos relacionales. Asimismo es preciso interpretar este agenciamiento en el contexto de modernización cultural que se produjo en Buenos Aires de las primeras décadas del siglo XX y en un marco más amplio, incluso más abarcativo que el social. La sociedad argentina de fines del siglo XIX y principios del XX venía experimentando grandes transformaciones a nivel social, económico, político y cultural y también los actores sociales que la conformaban que vieron afectadas sus identidades de clase. Por su parte, entre principios del siglo XX y 1916 se vislumbraron cambios en el mundo de los intelectuales. Aunque inciertas, aparecían alternativas profesionales para los que querían dedicarse a las letras, había quienes en el estado por ejemplo, se hacían una fuente de ingresos ya sea como maestros o bibliotecarios. Con el aumento de las tasas de alfabetización empezaba a acrecentarse un público de revistas y libros y nuevos sectores sociales accedían a los circuitos del consumo cultural. Este proceso se aceleró precisamente en los años veinte y el mundo de los intelectuales tendría en ese marco mayor autonomía. (Cattaruzza, 2012: 69). Este escenario coincide también con el contexto histórico donde comenzaba a perfilarse una crisis de las elites en Argentina. Por esto, a la luz de los trabajos de Vázquez (2019) en diálogo con los aportes de Derrida y Roudinesco (2009) sostenemos la hipótesis de que Ocampo se posicionó como una articuladora de lo público y privado y asimismo como una "heredera infiel" que hereda por la transformación 6 . Esta última noción permite pensar a una mujer activa que juega y negocia hábilmente con los varones notables, reconociendo sus limitaciones pero articulando vínculos que permitieran sortearlas. Así, transforma el ideario de la elite a la que pertenecía por medio del agenciamiento literario, artístico y cultural. En otras palabras podemos decir que Victoria "hereda para salvar la vida" (Derrida y Roudinesco, 2009: 12). Este agenciamiento es preciso enmarcarlo en el contexto de una sociedad con una cultura de masas en crecimiento, donde se producía una deconstrucción de jerarquías tradicionales, una reducción de la anterior nitidez de las relaciones de clase, y se incorporaban sectores antes postergados (Hall, 2017: 28-29). Como hábil observadora y escritora de su realidad y su contexto, en su Autobiografía Victoria no solo periodiza el cimbronazo en su vida personal y pública sino que también le da un nombre a ese proceso: "Viraje"7. Así por medio de la escritura a la vez que reconstruye su lugar de agencia deja impresa la tradición por la cual pretendía ser leída8.

\section{LOS INICIOS (1924)}

n esa transición que deja impresa Ocampo en su escritura que podríamos denominar
de la domesticidad a la escritura y la gestión artística y cultural, existieron para ella dos episodios centrales relacionados con varones ligados al mundo de la cultura y el arte, a los que 
les dedicó varias páginas, por un lado la llegada de su admiradísimo Tagore a la Argentina9 y por otro, el vínculo que entabló con Ansermet ${ }^{10}$. En ambas relaciones puede advertirse el rol de Victoria como gestora y la negociación que entablo con ellos, para lograr construir su agenciamiento a partir de la legitimación de la mirada que le devolvían esos varones. Si como dice Vázquez (2019) Victoria jugaba para ganar, en el contexto de los veinte sabía que debía lidiar y negociar con quienes monopolizaban el capital cultural. En su escritura autobiográfica Victoria establece como mojón al año 1924 y señala que esa fecha marca la salida de la cárcel que había significado para ella su matrimonio con Estrada luego de haber abandonado la primera de las prisiones, la familiar:

1924 parece haber sido un hito en mi vida. Ese año me habitué a realizar (en el sentido ingles del término, es decir, a comprender) que por fin vivía sola (había alquilado mi casa en calle Tucumán; habitaba, sola, en un departamento de la calle Montevideo), que por fin había reconquistado (o conquistado), hasta un cierto punto, mi libertad perdida en el matrimonio, al salir de la prisión del convento familiar (Ocampo, 1982: 7, grifos en el original).

Por lo expresado por Victoria, allí realiza un pasaje del silencio a la palabra y a la acción y de esa forma recobra su libertad. Este proceso interior coincide con la adquisición de un "cuarto propio" donde Victoria no solo muestra la experiencia personal de mudarse sola, luego del fracaso de su relación matrimonial con Luís Bernardo de Estada y de experimentar su amor clandestino con Julián Martínez, sino el comienzo de su consolidación en la escena pública de los veinte donde conjugó su rol de escritora con el de mecenas. Será con la llegada del poeta hindú donde pueden hallarse los primeros indicios de una Victoria que opera como anfitriona, hospedando a este en Miralrío, en una quinta del marido de su prima, luego de la negativa paterna. Recurre entonces a varones para llevar a cabo su propósito. Esto ocurrió antes de los que pueden considerarse los inicios de Sur como proyecto, que datan de 1929. Precisamente donde Victoria realiza el corte en su periodización y conjuga de manera magistral lo público y lo privado.

Con la llegada de Tagore a Buenos Aires en 1924 Victoria tomó a su cargo el hospedaje del Premio Nóbel de Literatura que admiraba desde 1914 por su obra Gitanjali y lo albergó durante casi dos meses. Este había sido invitado por los festejos del Centenario de Perú, pero por razones de salud le aconsejaron que se quedara en Buenos Aires:

La presencia súbita y real de ese hombre distante, tan familiar en mis sueños, tan íntima a mi corazón, cuando no conocía de él más que sus poemas, me paralizó. Reacción habitual ante un escritor. Hubiera querido huir enseguida. Caí en el mayor mutismo y toda la conversación estuvo a cargo de A.A. Los propósitos que ella tenía me preocupaban. Las cosas que decía me molestaban. Interrumpí bruscamente la entrevista, prometiéndome un desquite en la próxima ocasión, esa ocasión que iba a fabricar. Corrí a casa de mis padres. Les rogué que me prestaran Villa Ocampo por una semana. Rehusaron. Me asaltó la idea de pedir ayuda al marido de una 
prima, R. de L.M. Consintió gentilmente en cederme su quinta en San Isidro, Miralrío, por una semana. Tuve la sensación de que me salvaba la vida (Ocampo, 1982: 25-26).

Aquí puede observarse una tensión de género en ese vínculo, donde Victoria parece ubicarse en un lugar de subordinación frente al poeta. Con relación a las identidades de género que se proyectan en esos intercambios muestra una especie de sometimiento hacia Tagore, desde un lugar de inferioridad frente a un varón que ella consideraba distante y por su parte deja entrever la parálisis que le provocaban los escritores varones. Asimismo se pone al servicio del hindú y dispone de dinero y personal para garantizar la estadía. Victoria negocia con los varones ligados a la cultura y por ellos. Se identifica además como admiradora, mientras que los varones la identifican como benefactora y gozan de sus recursos económicos. Coincidimos con Podlubne (2016) cuando considera a la autobiografía de Ocampo como una aventura espiritual donde ésta se retrata siempre fortalecida de las caídas, sobrellevando todos los dramas que describe. Aunque la escritura de Ocampo tiene una clara intencionalidad que no desconocemos, esta puede ser, a partir de la utilización de la categoría de género, la puerta para analizar las estrategias de una hábil jugadora en un mundo androcéntrico. Retomando a Vázquez (2019), podríamos decir que Ocampo juega para ganar, en un espacio dominado por los varones y como mujer se fabrica un desquite. Es interesante pensar también que:

La "experiencia" subraya la localización crítica de un sujeto que interpela los códigos dominantes desde un lugar de enunciación siempre especifico, materialmente situado, y designa procesos de actuación que dotan a un sujeto de movilidad operatoria para producir identidad y diferencia en respuesta a ciertas coyunturas de poder (Richard, 2018: 31).

A Tagore Victoria le adjudicará la misma edad que en ese momento tenía su padre, modales que lo ligaban a lo aristocrático y parecerse a un "niño mimado" (Ocampo, 1982: 25-27). Es en esa entrada para tomarlo bajo su cuidado donde puede empezar a percibirse el rol de Ocampo como gestora:

Volé de nuevo al Plaza Hotel a anunciar a Elmhirst que en el espacio de dos días todo estaría listo... El tiempo necesario para limpiar los cuartos, transportar a Milrarío ropa blanca, cacerolas, vajilla, gente de servicio (la mía). Yo misma me instalé en Villa Ocampo con Fani, para estar cerca de Tagore y a su servicio (Ocampo, 1982: 26).

Asimismo, también realizaría otras gestiones artísticas y culturales que pueden reconstruirse por las huellas de su escritura y mediante alguno de los rastros de las revistas de actualidades de la época. Este es por ejemplo el marco en que Ocampo introduce a Ansermet en la elite porteña, segundo varón abordado en "Viraje". También lo intercepta como benefactora en la Asociación del Profesorado Orquestal (APO). Según ella misma 
expresa, le comentaron que los músicos no percibían un sueldo y solo disponían de una magra subvención de la Comuna. Al concurrir Ansermet a tomar el té por su invitación, es donde Victoria comienza a interesarse sobre que podía hacerse en pos de dicha institución: "Yo contaba con el apoyo que sin duda Marcelo de Alvear, entonces presidente y amigo personal, podría darnos si lograba interesarlo en esta empresa cultural" (Ocampo, 1982: 89).

A partir de su vínculo de amistad con el entonces presidente, Victoria puede entenderse como quien habita un lugar de vacancia por parte del Estado. Alvear representaba lo más refinado de la elite en el poder, una flexión elitista dentro del gobierno radical. Victoria parece entender el entramado político desde los parámetros que lo habían hecho sus antepasados. Lo que en el XIX había sucedido en el marco de las familias como la suya que se confundían con la historia de la Nación argentina, encontraba en los XX en la figura de Alvear a quien operaba como antes lo habían hecho los amigos notables de sus ancestros: Sarmiento, San Martín y Roca, entre otros. No es casual que Victoria lo recupere como figura política y amigo en la escritura. Tampoco es extraño que se haya acercado a este para ganarse un lugar en lo público ni que buscara en ese clima de modernización cultural, insertar a Ansermet para educar al público porteño, luego de convencerlo de que volviera a Buenos Aires en 1925, abandonando este los ballets rusos:

Aquí formaba el gusto de un público nuevo, formaba una orquesta, formaba músicos; en el peor de los casos y aunque lo que soñábamos para la APO no se realizara totalmente, su trabajo iba a dejar forzosamente huellas en nuestra capital [... . Era, en nuestro país, la época de siembra. Todo ha probado, con el correr del tiempo, que no me equivocaba al pensarlo. Gracias sean dadas a aquel generoso sembrador (Ocampo, 1982: 95-96).

Como señaló Losada (2009: 190):

En la primera mitad del siglo XIX, las nociones identitarias de elite estuvieron fuertemente asociadas a cualidades desprendidas de la dimensión política. En la segunda mitad del ochocientos y en el amanecer del siglo XX, en cambio, los atributos de una posición encumbrada hicieron referencia a aspectos más relacionados con el gusto, el refinamiento y el estilo de vida.

No es aventurado pensar en Alvear como el "generoso sembrador" en una época considerada dorada, en contraste con Perón quien gobernaba cuando Victoria comenzó a escribir su Autobiografía y con el cual mantendría durante toda su vida diferencias insalvables, salvo el único reconocimiento que le valió en 1954 la ley que daría entidad a los hijos considerados "ilegítimos" (Ocampo, 1954). También es interesante pensar que la actuación de Victoria remite a un cierto nivel de cultura que puede entenderse como un atributo di- 
ferenciador de clases (Bourdieu, 1988), en un contexto donde precisamente las elites iban perdiendo atributos culturales y "espirituales":

Los bolsillos de muchos amigos [y los míos, por cierto] estuvieron abiertos para la APO y así logramos una suma semejante a la que había acordado la Municipalidad. Marcelo de Alvear se interesó en los conciertos y asistía a los matutinos [había a precios populares los domingos por la mañana]. También iba Sagarna, el Ministro de Educación, y Arce, presidente de la Comisión de Presupuesto [creo]. Unos concurrían gracias a las gestiones de la APO, otros, gracias a las mías (Ocampo, 1982: 90-91, grifo en el original).

Más allá de este lugar, es preciso ver que el rol que jugó Ocampo fue posibilitado por un Estado mínimo en cuestiones culturales. Durante el gobierno de Marcelo T. de Alvear, Victoria pudo empezar a construirse un espacio como anfitriona, un lugar que no necesariamente venía a romper con el ideal de lo permitido en ese contexto para una mujer de la elite y que leído desde el presente, puede pensarse que anticipaba de alguna manera su labor en Sur. $Y$ este agenciamiento puede entenderse también desde la clara conciencia de Victoria sobre qué lugares podía empezar a ocupar siendo una mujer de su posición social y cuales le estaban vedados. De allí las negociaciones y articulaciones de vínculos con los varones notables que eran quienes habilitaban y legitimaban, o descartaban y desechaban. Una mujer como Victoria disponía de un impresionante caudal económico pero a la vez tuvo que sobreponerse en reiteradas ocasiones a los numerosos "no" que recibía de los varones notables. Uno de los conocidos rechazos que se suman a una extensa lista fue al momento de escribir De Francesca a Beatrice ${ }^{11}$ donde tanto Groussac como Estrada la descartaron. Sin embargo a partir de esa negativa se produjo la conexión con Ortega y Gasset quien publicó su libro con su epílogo por Revista de Occidente. Con esto queremos precisar que donde hay poder hay resistencia y Ocampo logró por su agenciamiento sobreponerse en reiteradas ocasiones a las negativas de los varones hasta constituirse un lugar, a partir de un interesante trabajo relacional que incluía la "amistad" y la "beneficencia". Con claras asimetrías en esa amistad, podemos afirmar que es el género lo que determina esos vínculos, ya que para salir a gestionar en el espacio público ella mira y se mira a través de los varones. Sus vínculos, al menos en lo que manifiesta en su escritura en el contexto en que situamos este trabajo, es decir en los veinte, son heteronormados y es allí donde precisamente opera la "amistad". Es entonces donde se separan de las políticas públicas y, en todo caso, resultan ser operaciones en el interior del campo intelectual y en el interior de una red de amigos intelectuales. Por eso es interesante pensar los vínculos de "amistad" a partir del cruce entre género y clase ya que esto puede comprenderse con relación a cómo sus antepasados entendían la historia de la Nación como la de sus familias, a partir de redes de parientes y amigos y cómo Victoria recupera ese legado 
(aunque lo transforme) al momento de estrechar vínculos (Ocampo, 1979). Esto ilumina desde la categoría de género en interrelación con la clase, las estrategias de Ocampo para ser parte de una sociabilidad y un ambiente cultural con una notable impronta patriarcal y más aún lograr una proyección pública12. Es por eso que en esa construcción identitaria (Hall, 1996) Victoria encarnó por medio de la transformación a la heredera de una elite en retroceso ${ }^{13}$. Con relación al estreno de El Rey David en agosto de 1925, dice Victoria: "Me tocó el papel de recitante. Jamás habían soñado en confiárselo a una mujer [...] Ansermet me elegiría como recitante" (Ocampo, 1982: 100-101).

Victoria señala irónicamente me tocó, asimismo a Ansermet lo emplaza como quien la elige. Es interesante pensar aquí en cómo Victoria se construye y reconstruye a partir de la mirada masculina. Tal como lo expresó Hall el concepto de identificación remite a una construcción, un proceso que no termina. Es en suma un proceso de sutura ${ }^{14}$. Por tanto analizar la Autobiografía de Ocampo nos habilita a enfocar nuestro trabajo sobre la noción de "espacio biográfico" teniendo en cuenta el instante y la totalidad desde una perspectiva transversal donde puede leérselo desde lo cultural, simbólico y hasta lo político, apuntando al abordaje de las narrativas del yo (Arfuch, 2010: 17-18). Hablamos en concreto de diversidad, hibridación, multiplicidad y recuperamos un concepto de identidad que remite por tanto a lo estratégico y posicional. Este concepto admite que las identidades se construyen de diversas maneras por ejemplo a partir de prácticas, discursos y posiciones. De allí un aporte sustancial de Hall (1996: 18): "Las identidades, en consecuencia, se constituyen dentro de la representación y no fuera de ella". Dicha construcción se da a través de la diferencia y allí aparece un tópico no menor al respecto su relación con el otro. En ese entramado teórico se liga a importantes aportes como los de Butler, Laclau y Derrida. Laclau señaló que una identidad social en cuanto a su constitución es un acto de poder. Derrida afirmó que en dicho proceso se excluye y jerarquiza (apud Hall, 1996: 19). Victoria muestra no solo el conocimiento personal del entonces presidente, ministros y funcionarios sino que contaba con un capital relacional que le permitía unir las gestiones del Estado con las suyas. En ese contexto fue clara su influencia en el ámbito cultural porteño. Retomando la hipótesis de Maria Celia Vázquez (2019) que señala que Ocampo intenta agenciarse un lugar en el espacio público a través de una voz propia articulando lo privado y lo público, sostenemos que Victoria lo logra a partir de su rol como escritora y gestora artística y cultural, lugar que le daba un posicionamiento de poder mucho más notable, ya que la habilitaba en la toma de decisiones y contactos que luego profundizaría con Sur articulando redes intelectuales e intercambios a lo largo del mundo. La Ocampo que se consolida en los treinta es deudora de todas las experiencias y prácticas de los veinte, donde comenzó a posicionarse, negociando con los varones notables. Hábilmente se posicio- 
naría y habitaría estratégicamente espacios deseados por las elites en retroceso y de escasa participación para las mujeres, aún las de su clase. En esa profunda participación de Victoria, para 1927 la subvención de la APO aumentó a cien mil pesos, cuando antes llegaba a los 30 mil. Sin embargo, las tensiones y conflictos no serían pocos, ya que el Directorio y la Comisión de Cultura descartarían por mayoría a Ansermet y contratarían al norteamericano Hadley. Allí Victoria se retiraría de la institución por ese mal trago y dejaría de ser su socia protectora, pero luego lograría traer nuevamente a Ansermet. Como cierre de este pasaje, Ocampo transcribe una carta de Ansermet en el medio del conflicto con la APO que es sumamente ilustrativa del contexto de los veinte en Argentina y el impacto sobre las elites: "Es necesario obrar y que ustedes los verdaderos (quería decir los verdaderos argentinos) se afirmen en la acción y en las obras. [...] Y usted bien sabe que es siempre el individuo el que decide, jamás la masa amorfa..." (Ansermet en Ocampo, 1982: 111, grifo en el original).

Durante los siguientes años, a partir de lo que podemos recuperar por algunas revistas argentinas de actualidades de la época Victoria hizo nuevas intervenciones como recitante. En la revista El Hogar se la encuentra en agosto de 1928 con motivo de haber formado parte de un festival organizado por el Cervantes donde recitó poesías de autores contemporáneos en beneficio de la Casa del Teatro (FESTIVALES DE BENEFICENCIA, 1928: 31).

Esta aparición de Ocampo es recogida en la Sección "Festivales de Beneficencia" cuestión que es importante para pensar que su irrupción en la esfera pública no es necesariamente contradictoria con los ideales de feminidad de la época ${ }^{15}$. Para septiembre de 1928, en El Hogar puede leerse "SEÑORA VICTORIA OCAMPO: que en el mismo festival de Los Amigos del Arte recitó, con su reconocido talento, algunas poesías de Baudelaire, considerado como uno de los poetas más difíciles para interpretar" y allí la foto de González Arrili muestra a una Ocampo posando. Del mismo fotógrafo también hay una foto de la sala de conciertos bajo el lema EN LOS AMIGOS DEL ARTE donde se señala "durante la fiesta en que intervino la Señora Victoria Ocampo y la Sociedad del Cuarteto", que ejecutaron números de Debussy y Glazounow. (NOTAS DE LA SEMANA, 1928: 42). Ya en 1924 con la llegada de Tagore, Victoria no solo había hecho que Ricardo Güiraldes fuera a cantarle y tocar la guitarra, sino que había invitado al cuarteto de los Castro que tocaron Borodin, Ravel y Debussy (Ocampo, 1982: 31). Por todo lo señalado hasta aquí es posible ver a una Victoria activa, múltiple y nómade de acuerdo con los diferentes escenarios y contextos por los que atravesaba, esto nos permite volver sobre la cuestión del sujeto y su agencia y asimismo retomar la idea de pose apuntada exquisitamente por Molloy (1996). En este sentido es preciso recordar que las imágenes remiten a sujetos pero sobre todo a escenas culturales donde se enfrentan, se niegan o reconocen nuevas formas de "ser en sociedad "o de "ser en la nación" (Molloy, 2012: 12). 


\section{LA APERTURA (1929)}

$\mathrm{E}$ I cierre o más bien la apertura de otra etapa para Victoria se ubica en 1929 y coincide en su obra literaria con "Quiromancia de la Pampa", ensayo publicado en La Nación, que como apunta Vázquez (2019: 33) inicia y adelanta los ensayos ${ }^{16}$ que serán ampliamente conocidos en los treinta a partir de las plumas de varones de la talla de Scalabrini Ortiz, Martínez Estrada y Mallea. Sin desconocer la originalidad de Ocampo y sus rompimientos de género, asimismo podemos pensarla en una continuidad con el ideario de las elites que a comienzos de siglo comenzarían en Argentina a ver con recelo el avance de una cultura de masas, incluso a escala transnacional. En un escrito del hijo de Tagore que data de fines de los años cincuenta y que se publicó en "Viraje", este realiza una perfecta descripción de Victoria donde expresa: "Sabía relacionarse con la gente y obtener lo que deseaba." (Tagore, 1958 en Ocampo, 1982: 72).

Asimismo la define como "escritora" y "patrocinadora de manifestaciones de arte" (Tagore, 1958 en Ocampo, 1982: 71) y relata que cuando su padre quiso realizar en París una exposición de pinturas en 1930 y se encontró con dificultades:

Cablegrafió a la señora Ocampo pidiéndole ayuda. Ella llegó inmediatamente y, sin el menor esfuerzo -al menos eso nos pareció a nosotros-, hizo todos los arreglos para una exposición. Aseguró el Teatro Pigalle, organizó la publicidad necesaria y en pocos días las pinturas estuvieron expuestas (Tagore, 1958 en Ocampo, 1982: 72).

La labor de mecenazgo y beneficencia de Ocampo no solo es anterior a Sur sino que también puede entenderse en un marco transnacional. Victoria describe en su Autobiografía el episodio al que refirió el hijo de Tagore y apunta:

Tagore se distraía en pintar y dibujar (había comenzado a hacerlo en San Isidro), cuando lo reencontré en Cap Martin. Pude convencer a Georges Henri Rivière y a Madame de Noailles para organizar una exposición de esas pinturas y dibujos en París. Es decir, Rivière la organizó y Ana de Noailles escribió el prefacio del catálogo. Tagore estaba tan contento como un adolescente que recibe un premio inesperado (Ocampo, 1982: 36-37).

En la conjunción de la escritora y la gestora, Victoria Ocampo articuló como mujer de la elite lo público y privado en el marco de la modernización cultural que experimentaba Buenos Aires por esos años y las transformaciones que venían produciéndose en Argentina de cara a una sociedad de masas. Ese interesante entrecruzamiento de lo público y lo privado, estaría marcado por: "Ese deseo de ir más allá de lo individual, de Francesca a Beatrice" (Ocampo, 1982: 125). 


\section{REFLEXIONES FINALES}

【os aportes de los estudios de género nos propiciaron herramientas medulares para nuespúblico y lo privado.

Con corrimientos de género notables para una mujer de su época y su clase, Ocampo negoció y jugó para ganar. Sobreponiéndose ante los innumerables "no", o en palabras de Meyer (1981) batallando "contra viento y marea", recurriría a múltiples estrategias para posicionarse y proyectarse en la esfera pública.

La noción de "heredera infiel" (Derrida; Roudinesco, 2009) nos permitió leer en los veinte a una Ocampo escritora y gestora artística y cultural, reproblematizando aspectos abordados preliminarmente en González (2018) en diálogo con el aporte de Vázquez (2019). Esto nos permitió trabajar interdisciplinariamente para comprenderla como una articuladora de lo público y privado y asimismo como una "heredera infiel", que hereda por la transformación. Las gestiones desarrolladas por Ocampo fueron entendidas no solo en el marco de las áreas de vacancia que dejaba el Estado en materia cultural, sino en los inicios de una sociedad de masas donde las elites habían empezado a perder sus atributos y espacios y comenzaban por tanto a desearlas.

La categoría de género en interrelación con la clase nos permitió abordar las estrategias de Ocampo para ser parte de una sociabilidad y un ambiente cultural con una notable impronta patriarcal y más aún lograr una proyección pública. Nuestro análisis enfatizó sobre la articulación de la escritora y la gestora y de lo público y lo privado. Nomádica, múltiple y contradictoria, como mujer de su clase y hábil jugadora, Ocampo recurrió a múltiples estrategias y contactos. Arriesgando y sobreponiéndose, supo ganarse un lugar en el espacio público que se profundizaría a partir de los treinta.

\section{NOTAS}

1 Aunque el concepto puede ser considerado a partir de parámetros actuales, sin embargo entendemos que se convierte en una herramienta analítica interesante para abordar los inicios de la trayectoria pública de Ocampo. Aquí focalizaremos por razones de extensión sobre Victoria como gestora. Cabe aclararse que no consideramos al trabajo de Ocampo como gestora como un plus de su escritura, sino que ambos construyen la tradición desde la que pretende ser leída.

2 Esto puede analizarse incluso a escala transnacional. Por razones de extensión no profundizaremos sobre esta problemática, pero si es posible señalar para futuros abordajes que así como Ocampo en los veinte se posicionó para educar el gusto de los porteños, en los treinta con Sur señalará la intención de educar a Argentina y a una América por descubrir, sin darle la espalda a Europa. Véase: Ocampo, 1931.

3 Seguimos la reflexión en torno a la herencia presente en el diálogo entre Derrida y Roudinesco (2009). Allí los autores analizaron la influencia de los abordajes estructuralistas de los setentas y hasta qué punto el 
propio Derrida fue fiel e infiel con estos. Una reflexión sobre el tema se encuentra en Derrida (1995). A la luz de esos diálogos y aportes teóricos leemos a Ocampo, dando especial importancia al legado de su tradición familiar frente al que se mantuvo infiel. Más allá de los corrimientos que sin dudas realizó, es pertinente pensarla en continuidad con el ideario de una de las familias más encumbradas de la elite porteña y como parte de la clase dirigente. Por eso la leemos como "heredera infiel" ya que recibe un legado que transforma como mujer en un especial agenciamiento social, cultural, literario y artístico. Dice Roudinesco en su diálogo con Derrida que se hereda por la transformación y es en ese sentido que interpretamos a Ocampo como "heredera infiel". En concreto: "De aquí proviene la idea de que la mejor manera de ser fiel a una herencia es serle infiel, es decir, no recibirla literalmente, como una totalidad, sino más bien pescarla en falta, captar su 'momento dogmático'" (Derrida y Roudinesco, 2009: 10).

4 Arfuch (2010) realiza un abordaje sobre el tema a partir de los trabajos de Arendt, Elías y Habermas. En Arfuch (2016) retoma los aportes de los feminismos y los estudios de género en la subversión de la dicotomía público-privado, siguiendo los trabajos de Scott y Butler.

5 Vázquez (2019: 14) analiza a Ocampo como "cronista" y se posiciona sobre sus Testimonios, diez volúmenes publicados entre 1935 y 1977. Si bien no aborda su Autobiografía reconoce, siguiendo a Sarlo y Molloy, que toda la escritura de Ocampo es autobiográfica.

6 Algunas cuestiones iniciales fueron esbozadas en Echeverría y González (2019).

7 Es importante notar que el impacto de los inicios de una sociedad de masas y el corrimiento de las elites en Argentina marcan a Victoria en los veinte y con mayor fuerza durante el peronismo donde empieza a escribir su Autobiografía en 1952.

8 La Autobiografía de Ocampo está compuesta por seis volúmenes que comenzarían a publicarse luego de su muerte en 1979. Ellos son: Autobiografía I, El Archipiélago (1979), Autobiografía II , El Imperio Insular (1980), Autobiografía III, La Rama de Salzburgo (1981), Autobiografía IV, Viraje (1982), Autobiografía V, Figuras simbólicas. Medida de Francia (1983) y Autobiografía VI, Sur y Cía. (1984), todos editados por Revista Sur. Creemos acertada la diferenciación en dos momentos que realiza Podlubne (2016: 90) sobre la misma, los primeros tres volúmenes que refieren a su autorretrato personal y los tres últimos que se ligan a la imagen intelectual y pública que Victoria quiere dejar impresa. Sobre el inicio de esa creación de una imagen intelectual y pública a partir de Viraje posicionamos este trabajo.

9 Ese encuentro es abordado en la novela de Lojo (2004).

10 También desarrolla hacia el final de "Viraje" su vínculo con Keyserling y cuenta su conflicto personal que por razones de extensión dejaremos para futuros trabajos.

11 Dice Podlubne (2016: 90) retomando a Molloy que ese fue el primer gran paso de Ocampo en su carrera literaria a partir de una escritura que no solo alcanza una forma sino que se transforma en una cuestión pública.

12 El dossier a cargo de Caldo y Vignoli (2016) desde la perspectiva de género nos propició varios ejes para reproblematizar las experiencias y prácticas de Ocampo.

13 Hall (1996: 14) abordó el concepto de identidad en el marco de los debates ligados a los feminismos, estudios culturales, y la influencia del psicoanálisis referido al estudio de las subjetividades y lo inconsciente. De allí la pregunta ¿Quién necesita otro debate sobre identidad? Sobre ese interrogante ligó dos respuestas en primer lugar, el enfoque deconstructivo. Derrida dirá en ese sentido 'pensar en el límite'. En segundo lugar lo que Hall denomina la irreductibilidad del concepto y la ligazón a la política y la cuestión de la agencia. 
14 Estas y otras cuestiones han sido recuperadas en la obra de Arfuch $(2005 ; 2010)$.

15 Aunque en un espacio de análisis diferente al porteño es interesante retomar a de Paz Trueba (2011) quien analizó la beneficencia para fines del siglo XIX y principios del XX y planteó que para el interior bonaerense el protagonismo de estas mujeres en la arena pública no necesariamente puede entenderse como disruptor sino como fiel al ideal de feminidad esperado socialmente para la época.

16 La autora se refiere a lo que Gramuglio (2001) denomina "ensayo de tema nacional".

\section{REFERENCIAS BIBLIOGRÁFICAS}

ARFUCH, L. Cronotopías de la intimidad. In: ARFUCH, L. Pensar este tiempo: Espacios, afectos, pertenencias. Buenos Aires: Prometeo, 2016. p. 217-263.

ARFUCH, L. El espacio biográfico: dilemas de la subjetividad contemporánea. Buenos Aires: FCE, 2010.

ARFUCH, L. Problemáticas de la identidad. In: ARFUCH, L. Identidades, sujetos y subjetividades. Buenos Aires: Prometeo Libros, 2005. p. 21-43.

BARRANCOS, D. Mujeres, entre la casa y la plaza. Buenos Aires: Editorial Sudamericana, 2008.

BOURDIEU, P. La distinción: crítica social del gusto. Madrid: Editorial Taurus, 1988.

CALDO, P.; VIGNOLI, M. Dossier Mujeres en la Historia de la Educación. Parte I: Maestras, prácticas, género e historia: hacia una historia de la educación en los tiempos de la consolidación de los sistemas educativos. Anuario de Historia de la Educación, Buenos Aires, v. 17, n. 2, p. 53-56, 2016.

CATTARUZZA, A. Historia de la Argentina 1916-1955. 2. ed. Buenos Aires: Siglo Veintiuno, 2012.

DE PAZ TRUEBA, Y. Mujeres y esfera pública: la campaña bonaerense entre 1880-1910. Rosario: Prohistoria Ediciones, 2011.

DERRIDA, J. Espectros de Marx: el estado de la deuda, el trabajo del duelo y la nueva internacional. Madrid: Editorial Trotta, 1995.

DERRIDA, J.; ROUDINESCO, É. Escoger su herencia. In DERRIDA, J.; ROUDINESCO, E. Y mañana, qué... 2. ed. Buenos Aires: FCE, 2009. p. 9-28.

ECHEVERRÍA, O.; GONZÁLEZ, M. S. Identidades y mundo sensible en los y las intelectuales de las derechas nacionalistas y liberal conservadoras frente a la irrupción de nuevos actores y nuevas prácticas. Argentina, primeras décadas del siglo XX. In: GRECCO, G. de L.; CALDEIRA NETO, O. (orgs.). Autoritarismo em foco: política, cultura e controle social. Río de Janeiro, Recife, Madrid: Autografia, Editora Universidade de Pernambuco, Ediciones Autónoma de Madrid, 2019.

FEMENÍAS, M. L. Itinerarios de teoría feminista y de género: algunas cuestiones histórico-conceptuales. Bernal: Universidad Nacional de Quilmes, 2019.

FESTIVALES DE BENEFICENCIA. El Hogar, Buenos Aires, 17 ago. 1928.

GARAZI, D. Experiencia, lenguaje e identidad: algunas notas sobre el concepto de experiencia en la obra de Joan W Scott. Trabajos y Comunicaciones, La Plata, n. 43, marzo 2016. 
GONZÁLEZ, M. S. Victoria Ocampo: escritura, poder y representaciones. Rosario: Prohistoria, 2018.

GRAMUGLIO, M. T. Posiciones, transformaciones y debates en la literatura. In: CATTARUZA, A. (org.). Crisis económica, avance del Estado e incertidumbre política (1930-1943): nueva historia Argentina. Sudamericana: Buenos Aires, 2001. v. 7.

GRAMUGLIO, M. T. Sur: constitución del grupo y proyecto cultural. Punto de Vista, Buenos Aires, año VI, n. 17, p. 7-9, abr./jul. 1983.

GRAMUGLIO, M. T. Sur en la década del 30, una revista política. Punto de Vista, Buenos Aires, Año IX, n. 28, nov. 1986.

HALL, S. Estudios culturales 1983: una historia teorética. Buenos Aires: Paidós, 2017.

HALL, S. Introducción, ¿Quién necesita "identidad"? In: HALL, S.; GAY, P. (orgs.). Cuestiones de Identidad cultural. Buenos Aires; Madrid: Amorrortu, 1996.

JELIN, E. Desigualdades de clase, género y etnicidad/raza: realidades históricas, aproximaciones analíticas. Ensambles, año I, n. 1, p. 11-36, 2014.

KADIR, D. Proemio: Personificaciones primarias/Colón autobiográfico. In: ORBE, J. (org.). La situación autobiográfica. Buenos Aires: Corregidor, 1995.

KING, J. Sur, estudio de la revista argentina y de su papel en el desarrollo de una cultura (1931-1970). México: FCE, 1989.

LOJO, M. R. Las libres del Sur: Una novela sobre Victoria Ocampo. Buenos Aires: Debolsillo, 2004.

LOSADA, L. Historia de las elites en la Argentina: de la conquista al surgimiento del peronismo. Buenos Aires: Sudamericana, 2009.

MATAMORO, B. Genio y figura de Victoria Ocampo. Buenos Aires: Eudeba, 1986.

MEYER, D. Victoria Ocampo: Contra viento y marea. Buenos Aires: Editorial Sudamericana, 1981.

MOLLOY, S. Acto de presencia: la escritura autobiográfica en Hispanoamérica. México: El Colegio de México, 1996.

MOLLOY, S. Poses de fin de siglo: desbordes del género en la modernidad. Buenos Aires: Eterna Cadencia, 2012.

NOTAS DE LA SEMANA. El Hogar, Buenos Aires, año XXIV, n. 987, p. 42, 14 sept. 1928. Disponible en: $<$ https://digital.iai.spk-berlin.de/viewer/image/798876050/42/\#topDocAnchor>. Acceso en el: 13 dic. 2019.

OCAMPO, V. Autobiografía I: El Archipiélago. Buenos Aires: Ediciones Revista Sur, 1979.

OCAMPO, V. Autobiografía IV: Viraje. Buenos Aires: Ediciones Revista Sur, 1982.

OCAMPO, V. Carta a Waldo Frank. Revista Sur, Buenos Aires, n. 1, 1931.

OCAMPO, V. Una nueva ley. Revista Sur, n. 231, 1954.

OCAMPO, V.; EL INFIERNO. Plus Ultra, año XIV, n. 158, 10 jun. 1929. Disponible en: <https://digital.iai.spkberlin.de/viewer/image/787261939/39/\#topDocAnchor>. Acceso en el: 13 dic. 2019. 
PAPEL Y TINTA. Fray Mocho, Buenos Aires, año XVII, n. 871, p. 41, 1 ene. 1929. Disponible en: <https:// digital.iai.spk-berlin.de/viewer/image/863994520/42/LOG_0082/>. Acceso en el: 13 dic. 2019.

PASTERNAC, N. Sur, una revista en la tormenta: los años de formación 1931-1944. Buenos Aires: Paradiso, 2002.

PODLUBNE, J. Victoria Ocampo. La autobiografía como aventura espiritual. Políticas de la Memoria, Buenos Aires, n. 17, verano 2016.

QUEIROLO, G. Victoria Ocampo (1890-1979): Cruces entre feminismo, clase y elite intelectual. Clío y Asociados, La Plata, n. 13, 2009.

RICHARD, N. Experiencia, teoría y representación en lo femenino-latinoamericano. In: RICHARD, N. Feminismo, género y diferencia(s). Santiago de Chile: Palinodia, 2018.

SARLO, B. Victoria Ocampo o el amor de la cita. In: SARLO, B. La maquina cultural. 3. ed. Buenos Aires: Seix Barral, 2007.

SARLO, B. Decir y no decir: erotismo y represión. In: SARLO, B. Una modernidad periférica: Buenos Aires 1920 y 1930. Buenos Aires: Nueva Visión, 1988.

SCOTT, J. Género e Historia. México: FCE, 2008.

SITMAN, R. Victoria Ocampo y Sur: entre Europa y América. Buenos Aires: Lumiere, 2003.

SOSA DE NEWTON, L. Diccionario Biográfico de Mujeres Argentinas. Buenos Aires: Artes Gráficas U. Chiesino S. A., 1972.

TOPUZIAN, M. Paul de Man: ¿la imposibilidad de la autobiografía? Anclajes, La Pampa, v. 7, n. 7, p. 255275, 2003.

VALOBRA, A.; NÁLLIM, J. Nuevas perspectivas historiográficas sobre mujeres, género y antifascismos en Argentina. Arenal, Granada, v. 23, n. 1, p. 143-169, 2016.

VÁZQUEZ, M. C. Victoria Ocampo, cronista outsider. Rosario-Buenos Aires: Beatriz Viterbo-Sur, 2019. 